\title{
Saildrone-observed atmospheric boundary layer response to winter mesoscale warm spot along the Kuroshio south of Japan
}

\author{
Akira Nagano* (D) and Kentaro Ando
}

\begin{abstract}
Using an unmanned sailing vehicle, known as a Saildrone, we observed mesoscale and smaller scale structures of oceanic and atmospheric variables across the Kuroshio south of Japan during the winter of 2018/2019. From December 28 to December 29,2018 , the Saildrone crossed just north of the center of a very warm $\left(\sim 23^{\circ} \mathrm{C}\right)$ mesoscale spot in the Kuroshio centered around $31.5^{\circ} \mathrm{N}, 135.8^{\circ} \mathrm{E}$. The northerly winter monsoon wind was intensified by $\sim 2 \mathrm{~m} \mathrm{~s}^{-1}$ over the mesoscale warm spot (MWS) and accompanied by a submesoscale sea level pressure undulation of $\sim 1 \mathrm{hPa}$ possibly due to two oppositely rotating ageostrophic vortices. At this time, the wind reached a maximum speed of greater than $12 \mathrm{~m} \mathrm{~s}^{-1}$ and removed heat from the ocean at a rate of $1141 \mathrm{~W} \mathrm{~m}^{-2}$. Subsequently (January $3-5,2019)$, the Saildrone observed weakening of wind and heat release to the atmosphere on the southern edge of the MWS, which was associated with the approaching low-pressure system over the Kuroshio. The observed submesoscale structures of atmospheric and oceanic variables near the center of the MWS suggest that the atmospheric boundary layer responded to the MWS through the pressure adjustment mechanism in the Kuroshio, where in situ high-resolution measurements have not been performed before.
\end{abstract}

Keywords: Kuroshio south of Japan, Saildrone, SST, Mesoscale warm spot, Winter northerly monsoon wind, Latent and sensible heat fluxes, Air-sea interaction

\section{Introduction}

The Kuroshio, the western boundary current of the North Pacific subtropical gyre, originates east of the Philippines, flows northeastward through the East China Sea, proceeds south of Japan, and extends further eastward as the Kuroshio Extension (Nitani 1972). The Kuroshio transports a huge amount of heat from the tropics to the subtropics (e.g., Bryden and Imawaki 2001; Nagano et al. 2009, 2010). In the Kuroshio region, sea surface temperatures (SST) are relatively high compared with the interior central and eastern regions of the subtropical gyre. Cold dry wind from the Eurasian Continent blows over the

*Correspondence: nagano@jamstec.go.jp

Japan Agency for Marine-Earth Science and Technology (JAMSTEC), 2-15

Natsushima-cho, Yokosuka Kanagawa 237-0061, Japan warm Kuroshio region, particularly during the boreal winter, thus removing heat from the ocean (e.g., Hsiung 1986; Konda et al. 2010). Atmospheric variables such as sea level pressure (SLP), air temperature, and wind speed and direction have also been observed being affected by the high SST water in the Kuroshio region during the winter (e.g., Tokinaga et al. 2006; Tomita et al. 2013; Kawai et al. 2014).

SST varies across the Kuroshio, with sea surface water around the Kuroshio current axis being noticeably warmer than its onshore and offshore sides. Based on observations performed in June and July of 1977, the water temperature of the warm core water was higher than $28.5^{\circ} \mathrm{C}$ (Taft 1978). The water in the warm core was characterized by low salinity $(<33.9 \%)$ and low dissolved oxygen concentration principally related to the high SST. 
The warm core in the Kuroshio is observed to be approximately $50 \mathrm{~m}$ thick, as indicated by hydrographic casts (e.g., Worthington and Kawai 1972; Taft 1978; Nagano et al. 2009). Furthermore, warm core water properties are not uniform along the Kuroshio. Very high temperatures are observed at intervals of approximately $10-500 \mathrm{~km}$, i.e., mesoscale or smaller scales, along the warm core of the Kuroshio. Fuglister and Worthington (1951) observed similar anomalously warm spotty sea surface water masses along the Gulf Stream, the western boundary current of the North Atlantic subtropical gyre. Because of the very high SST in the Kuroshio, such mesoscale warm spots (MWSs) are considered to play critical roles in air-sea interactions.

The atmosphere in extratropical regions is considered to locally respond to spatial SST variation in two ways, which were both originally revealed operating to the atmospheric boundary layer over SST fronts in tropical regions. One is known as the pressure adjustment mechanism. An SST front induces positive and negative anomalies in SLP on the cold and warm sides of the front, respectively, and the generated pressure gradient modifies sea surface wind (Lindzen and Nigam 1987). The other is the vertical mixing mechanism. Strengthened vertical mixing in the atmospheric boundary layer over a high SST descends high wind momentum from aloft to the sea surface and enforces sea surface wind (Wallace et al. 1989; Hayes et al. 1989). These two mechanisms provide different structures of the atmospheric boundary layer. If the pressure adjustment mechanism operates, SLP is changed to adjust to wind change. Otherwise, SLP would not be modified. Thus, by examining oceanic and atmospheric variables, it can be elucidated how the atmosphere responds to a high SST of a Kuroshio MWS.

Knowledge on mesoscale or smaller scale variations of the Kuroshio and the overlying atmosphere is based mainly on oceanic and atmospheric surveys conducted by research vessels. Under severe weather conditions in the East Asian winter monsoon, air-sea interactions presumably occur associated with active heat release to the atmosphere (e.g., Hsiung 1986; Konda et al. 2010). However, because of stormy weather and rough seas during the winter, ship-based observations are frequently abandoned. Satellites permit near real time observation of variations in the ocean and atmosphere. Data assimilation techniques provide dynamically consistent data based on observations. However, satellite data for air-sea interaction studies, which resolutions are mostly approximately $0.25^{\circ}$ (e.g., Tomita et al. 2019), and assimilation data do not yet have enough spatial and temporal resolution to reproduce mesoscale or smaller air-sea interactions. Higher spatial and temporal resolution in situ data are required to reveal mesoscale and smaller wintertime airsea interactions in the Kuroshio region.
Various types of unmanned surface vehicles have been developed recently (e.g., Manley 2008). Saildrones (SDs) are a type of unmanned surface vehicle powered by winds (https://www.saildrone.com) and are currently being put into scientific research use (e.g., Meinig et al. 2015; Zhang et al. 2019). SDs can be at sea for several months, remotely controlled from land, and can transmit collected data to land via satellite communication in near real time. Measurements and data transmissions are maintained by a solar-powered battery management system. After being launched from port, SDs perform unmanned observations regardless of weather and ocean conditions and obtain data with minimal platform-induced atmosphere and ocean disturbances. At a sailing speed up to $\sim 8$ knots, SDs can also quickly reach predetermined observation areas and complete the spatially high-resolution observations in fairly short times at sufficiently short transects. Because of these advantages, we expect that observations by SDs can reveal the mesoscale and smaller scale oceanic effects on the atmospheric boundary layer.

Since September 2017, the Kuroshio has taken a stable current path, referred as the large-meander path, that is associated with a large southward meander south of Japan (Nagano et al. 2019). Several anomalously hightemperature spots are present along the warm core of the Kuroshio, as indicated by letter $\mathrm{W}$ in the satellite-based SST map on January 1, 2019 shown in Fig. 1. To reveal the horizontal mesoscale and smaller scale structures of the ocean and atmosphere near the sea surface, we performed a repeat observation by an SD across the MWS centered near $31.5^{\circ} \mathrm{N}, 135.8^{\circ} \mathrm{E}$, which has the highest SST. We found that wind is intensified over the MWS and that turbulent heat flux from the ocean to the atmosphere is large, likely resulting from the air-sea interaction over the spotty warm area of the Kuroshio. In this paper, focusing on influences of the MWS on the atmosphere and turbulent heat flux, we described the horizontal mesoscale and smaller scale structures of atmospheric and oceanic variables near the sea surface around the Kuroshio.

\section{Methods/experimental}

Figure 2 shows a diagram of the SD Generation 5 vehicle used for this observation. The SD is $5 \mathrm{~m}$ tall and $7 \mathrm{~m}$ long. An ultrasonic wind speed and direction sensor (Gill Instruments) was installed on the top of the sail $(5 \mathrm{~m}$ height). On the sail boom, sensors for measuring air temperature/relative humidity and air pressure were installed at heights of 2.4 and $0.3 \mathrm{~m}$, respectively. Atmospheric variables were collected at $5 \mathrm{~min}$ intervals. A downward looking infrared thermometer (Heitronics) was set on the boom at a height of $2.25 \mathrm{~m}$; however, this instrument did not collect data in the study region because it malfunctioned as described below. Four visible light cameras were also installed near the air temperature/relative humidity 


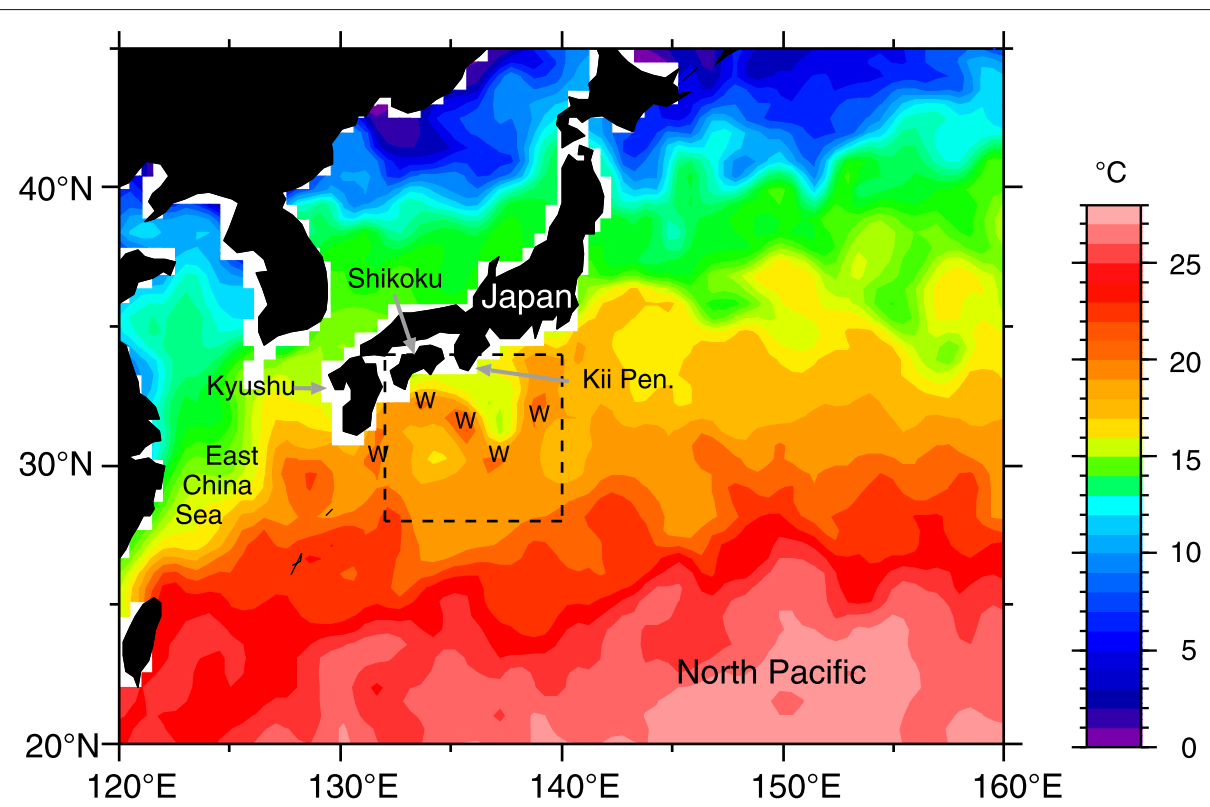

Fig. 1 Satellite-derived sea surface temperature map on January 1, 2019. Saildrone observations were performed in the region enclosed by the dashed square. The areas labeled with the letter W indicate anomalously warm spotty sea surface Kuroshio water masses

sensors on the sail boom, facing up, down, left, and right, and took pictures around the SD four times per day during daylight hours.

Water temperature, salinity, dissolved oxygen concentration, and chlorophyll- $a$ content were measured at 1 min intervals using a $\mathrm{CTDO}_{2}$ sensor and fluorometer (RBRoem C.T.ODO.FL) installed on the rear keel at a depth of $53 \mathrm{~cm}$. A downward looking $300 \mathrm{kHz}$ acoustic Doppler current profiler (ADCP) (Teledyne RD Instruments) installed at a depth of approximately $25 \mathrm{~cm}$ collected velocity vector data at 5 min intervals from approximately $6 \mathrm{~m}$ to $80 \mathrm{~m}$ depths. All the instruments were tested and calibrated by the manufacturers before the observations.

We determined in real time the SD track, referring to SST, sea surface salinity (SSS), current velocity, air temperature, relative humidity, and SLP derived from an ocean assimilation system based on the Hybrid Coordinate Ocean Model and the Global Forecast System of the U.S. National Centers for Environmental Prediction. Saildrone, Inc. operators performed observation along the track. Observations began on October 16, 2018, by launching an SD (Generation 4) from Guam. Unfortunately, after the launch, on October 24, the SD lost control on the way. Another SD (Generation 5) was then launched from Guam on December 5 and reached the region south of Japan on December 20 (Fig. 3a). Until December 30, the SD sailed across the Kuroshio twice as planned due to favorable winds from behind. However, the wind direction changed on December 31, making the wind inadequate for crossing the Kuroshio; therefore, the SD drifted to the southeast on the swift current. Eventually, a serious incident occurred on the SD on January 8, 2019, and data collection and transmission stopped probably due to vandalism by a fishing boat. The SD was then recovered on January 30. Therefore, we used data obtained from December 20, 2018, to January 8, 2019.

Based on the calibration after recovery, SST and SSS measurement accuracies were better than $0.0105^{\circ} \mathrm{C}$ and 0.1277 , respectively. SSS data collected by this SD observation were found to include a sensor drift after December 20, 2018. Assuming that there was no sensor drift until December 20, we performed a fitting of salinity values to a quadratic function and determined regression coefficients to obtain sensor drift using the least squares method. After subtracting sensor drift from the salinity data, we further removed noisy features using a 15 sampling length (15 min) median filter. The root-mean-square (RMS) difference of the corrected salinity data is 0.1610 . Although the RMS difference is comparable to the measurement error, results based on the SSS data should be carefully interpreted.

Applying the COARE 3.0b bulk flux algorithm (Fairall et al. 2003), we computed sea surface sensible and latent heat fluxes. Measurement of skin temperature was stopped on December 25, 2018, before the observation of the Kuroshio south of Japan. Because the SD did not measure shortwave and longwave radiation fluxes, we cannot perform skin temperature correction. Instead, we used the temperature data obtained by the $\mathrm{CTDO}_{2}$ sensor at 


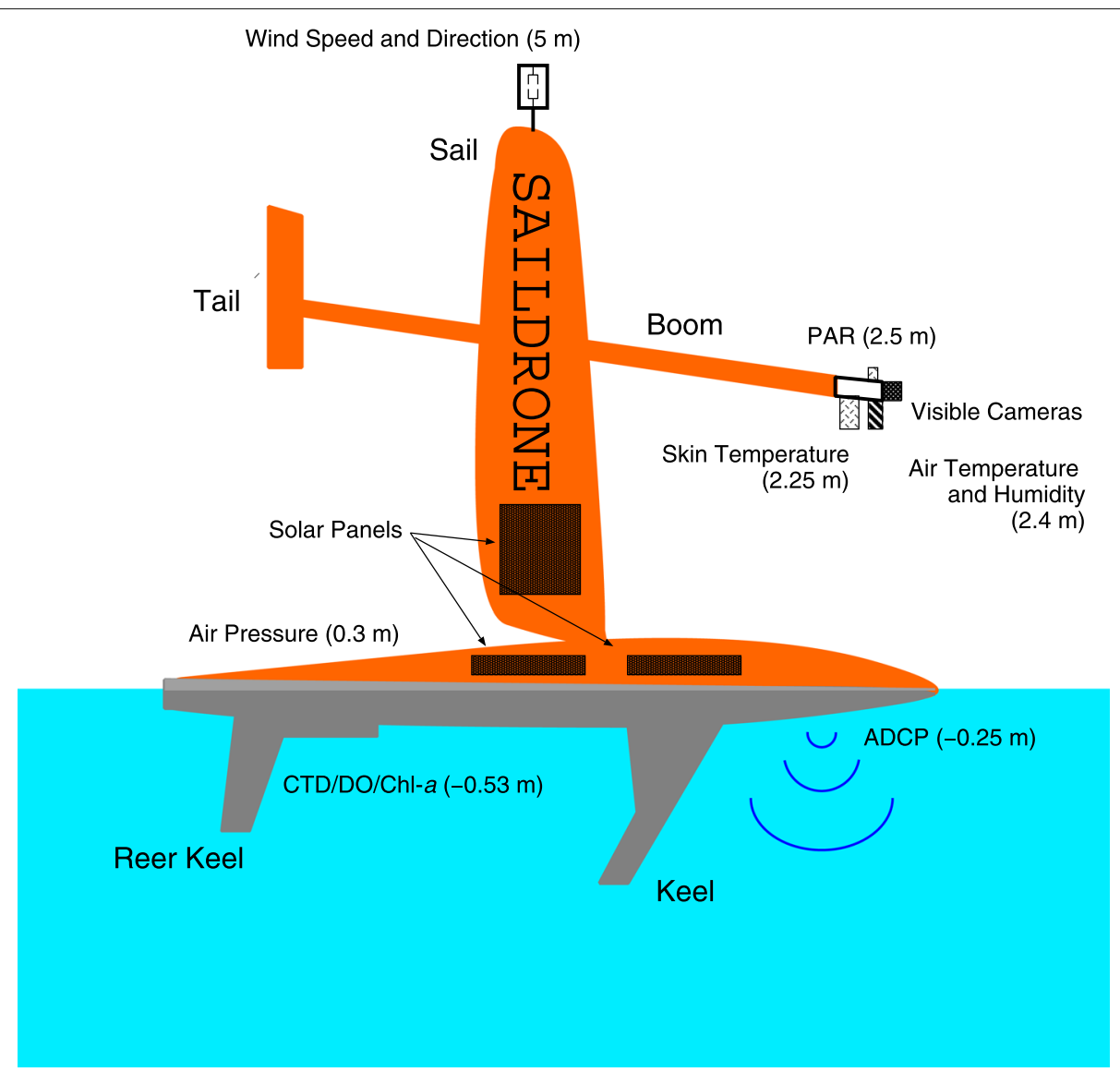

Fig. 2 Diagram of Saildrone Generation 5. The positive and negative numbers in parentheses indicate the heights of meteorological sensors and depths of oceanic sensors, respectively

a depth of $53 \mathrm{~cm}$ (Fig. 2) without skin temperature correction. Throughout the SD observations in the region south of Japan, we obtained continuous spatial variations in turbulent heat flux data at $\sim 2 \mathrm{~km}$ intervals along the track.

We used daily absolute sea surface height ( $\mathrm{SSH}$ ) data, i.e., delayed-time updated mapped SSH anomaly data (DT_SLA-H) added to the mean dynamic topography data (MDT_CNES-CLS13; Rio et al. 2011) and daily $1 / 4^{\circ} \times 1 / 4^{\circ}$ gridded SST data (NOAA OI SST V2 High Resolution Dataset; Reynolds et al. 2007) from December 21 , 2018, to January 8,2019 , in the region spanning $20-$ $45^{\circ} \mathrm{N}, 120-160^{\circ} \mathrm{E}$. SLP fields in this region were obtained from $1.25^{\circ} \times 1.25^{\circ}$ gridded data of the Japanese 55-year Reanalysis (JRA-55) conducted by the Japan Meteorological Agency (Kobayashi et al. 2015). We used $1 / 3^{\circ} \times 1 / 3^{\circ}$ gridded sea surface current velocity data from Ocean Surface Current Analyses Real-time (OSCAR; Bonjean and Lagerloef 2002), from December 21, 2018, to January 6, 2019. OSCAR data consist of sea surface current velocity vector constructed every 5 days based on satellite-sensed
SSH gradients and sea surface winds. Using OSCAR data, we evaluated divergence of currents.

\section{Results}

The Kuroshio south of Japan is illustrated by a sharp offshoreward increase in SSH (Fig. 3a). A tongue-like structure of warm sea surface water has been observed along the Kuroshio current by satellite SST measurements (Figs. 1 and 3a). The SD observations found the SST gradient to be greater on the inshore side of the current axis than the offshore side (Figs. 3a and 3b), as reported by Taft (1978). Throughout the observation period, the SDobserved SST change is mostly attributable to passages of the SD across the temperature front of the Kuroshio but not to periodic variations such as diurnal cycle (Fig. 4a). The SST in the Kuroshio region is higher than air temperature during the winter; in other words, air-sea temperature difference (SST minus air temperature) is positive (Fig. 3d). Thus, heat is released to the atmosphere (Fig. 3g), as observed in previous studies (e.g., Hsiung 1986; Konda et al. 2010). 

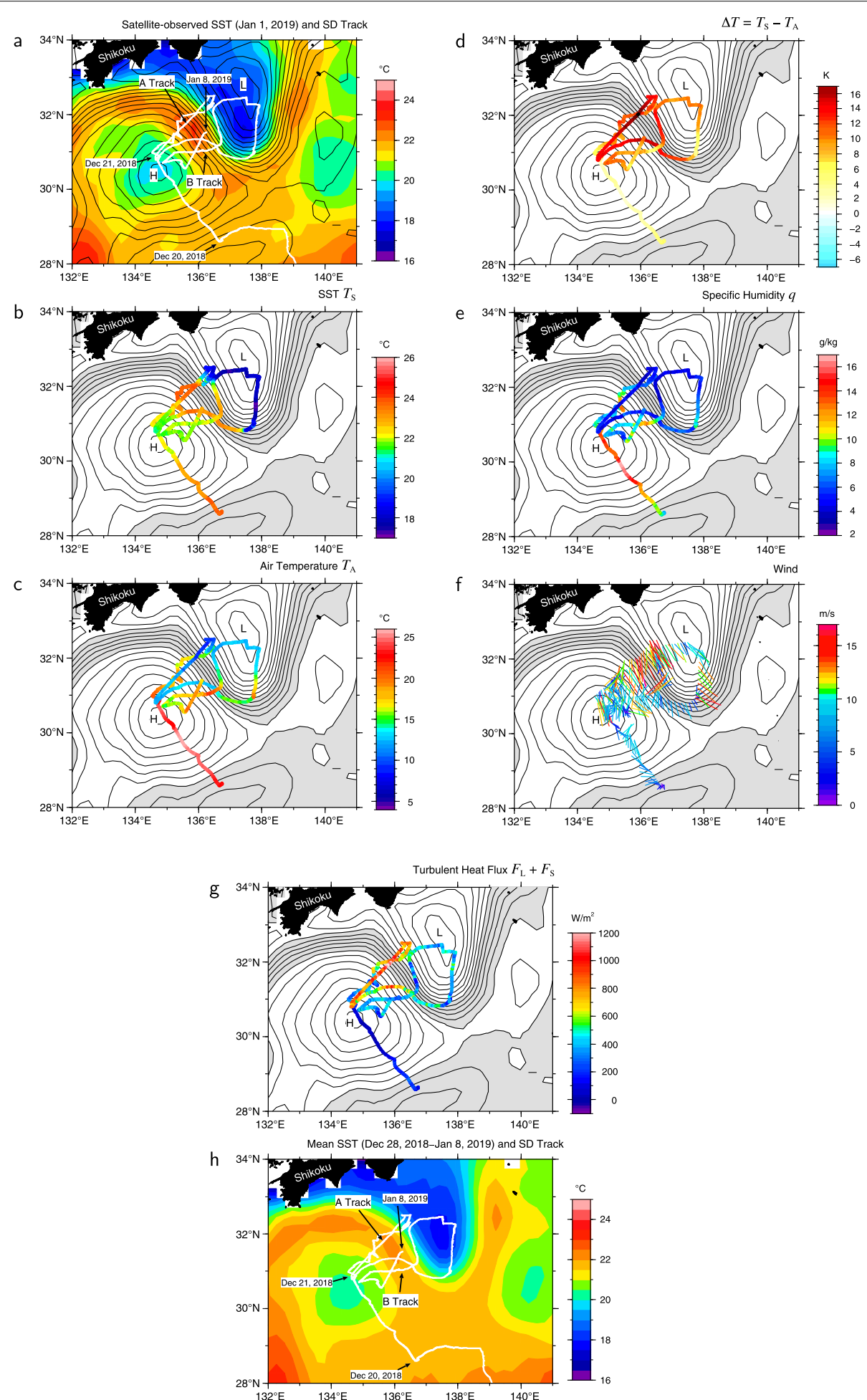

Fig. 3 Plots of a satellite-observed sea surface temperature (SST), b Saildrone-observed SST, c air temperature, d air-sea temperature difference, e specific humidity, $\mathbf{f}$ wind vector, $\mathbf{g}$ turbulent (latent plus sensible) heat fluxes on the Saildrone track and altimetric sea surface height (SSH, contours) on January 1, 2019, and $\mathbf{h}$ satellite-observed SST averaged from December 28, 2018, to January 8, 2019. In $\mathbf{a}$ and $\mathbf{h}$, the Saildrone tracks are illustrated by thick white line. The SSH contour interval is $10 \mathrm{~cm}$ and, except for $\mathbf{a}$, gray shaded areas indicate SSH values between $90 \mathrm{and} 140 \mathrm{~cm}$ 

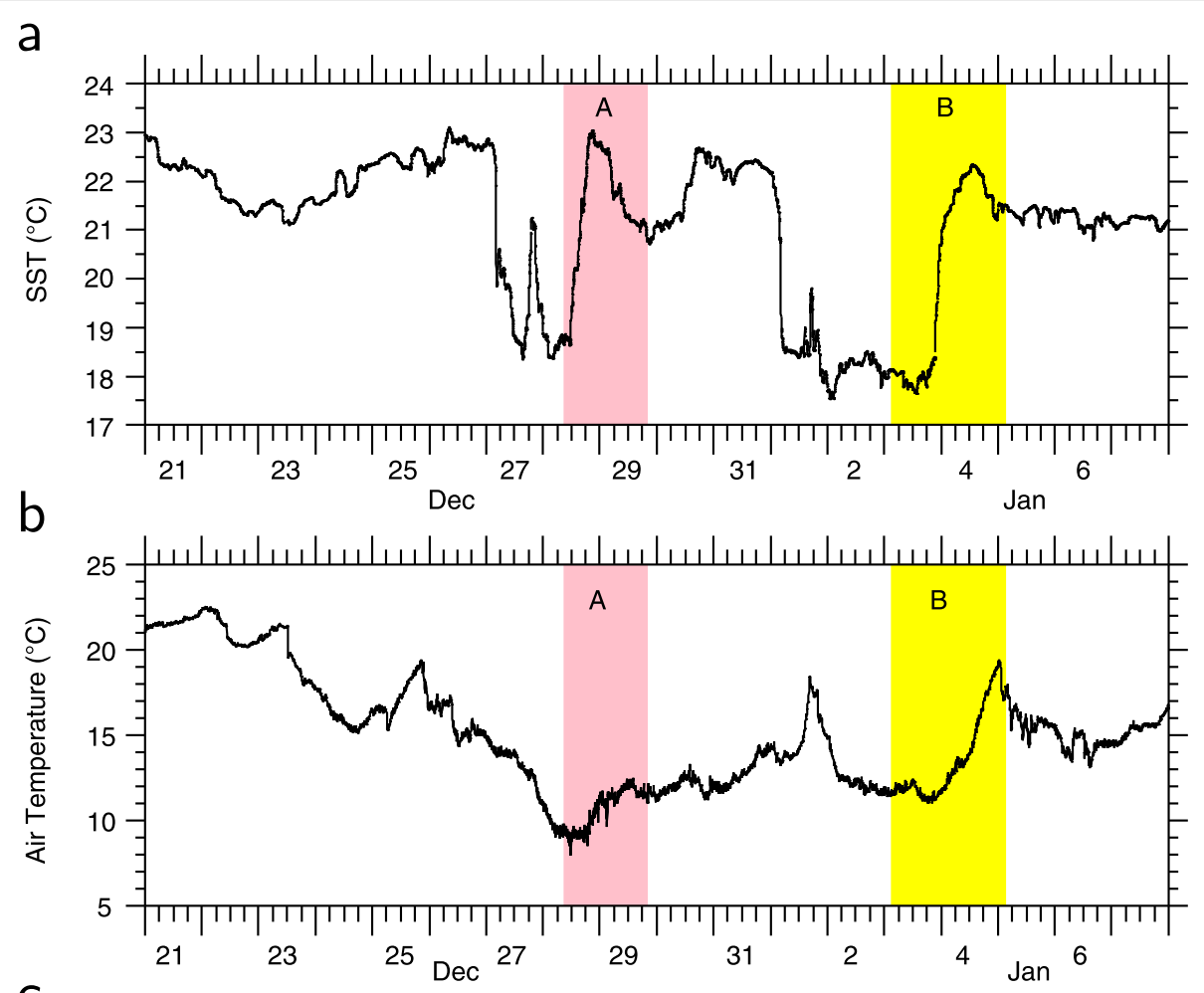

C

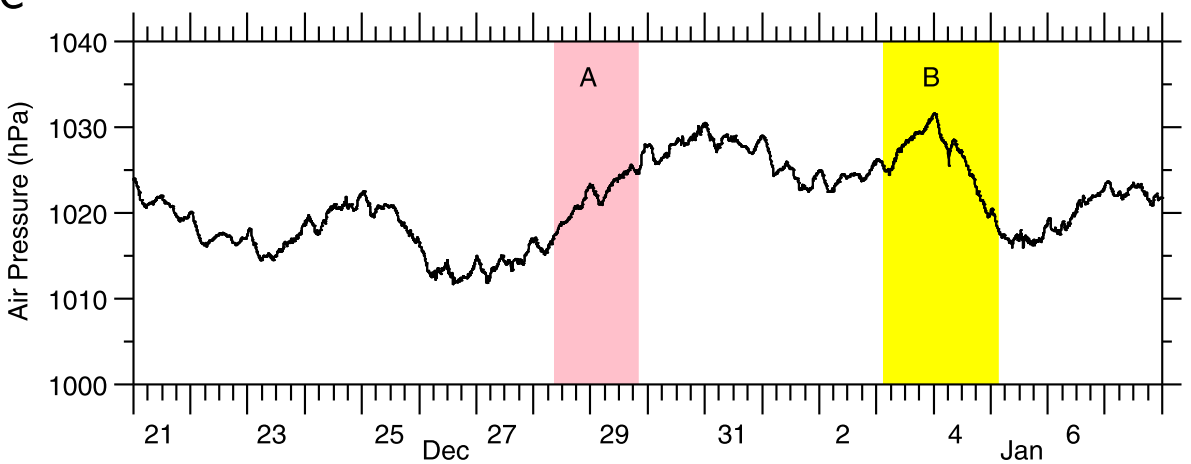

Fig. 4 Plots of Saildrone-observed $\mathbf{a}$ SST, b air temperature, and $\mathbf{c}$ air pressure with respect to time during the observation off the southern coast of Japan from December 21, 2018, to January 7, 2019. Periods of observations along the A and B tracks are indicated by pink and yellow bands, respectively

Additionally, spots of very high SST are found along the Kuroshio at approximately $50-100 \mathrm{~km}$ intervals (Figs. 1 and 3a), as Fuglister and Worthington (1951) observed in the Gulf Stream in the North Atlantic. The SD crossed twice the Kuroshio just north of the center of the MWS $\left(31.5^{\circ} \mathrm{N}, 135.8^{\circ} \mathrm{E}\right)$ and crossed the southern edge three times (white lines in Fig. 3a). The dimensions of the MWS parallel and perpendicular to the Kuroshio current direction were approximately 100 and $50 \mathrm{~km}$, respectively, making it the largest of the MWSs observed by satellite SST measurements in the region south of Japan during the study period. The SST around the center of the MWS is higher than $23^{\circ} \mathrm{C}$ (Fig. 3a). The MWS continued to exist in almost the same location for approximately two weeks from late December 2018 to early January 2019, as denoted in the map of satellite-observed SST averaged from December 28, 2018, to January 8, 2019, in Fig. 3h.

Meanwhile, atmospheric conditions over the region south of Japan greatly varied due to the passages of lowpressure systems during the observation period (Figs. 4b and 4c). Therefore, air temperature (Fig. 3c) and specific humidity (Fig. 3e) were different each time the SD crossed the Kuroshio. In particular, air temperature and specific humidity were low on December 28-30, 2018. During this period, SD-observed air pressure continued to increase (Fig. 4c) and cold dry northerly or northwesterly winds 
blew from the continent under typical winter weather conditions around Japan, as indicated by SLP maps based on the JRA-55 data in Fig. 5. The winter weather condition was persistent while the SD crossing the Kuroshio. The influence of the Kuroshio on the atmosphere is identified (Fig. 3f), and the winds were remarkably intensified over the Kuroshio from December 28 to December 30, exceeding $12 \mathrm{~m} \mathrm{~s}^{-1}$.

Similar enhancements of winds over high-SST areas have been reported in the tropical regions (e.g., Lindzen and Nigam 1987; Wallace et al. 1989; Hayes et al. 1989) as well as over the Kuroshio and the Kuroshio Extension (e.g., Tanimoto et al. 2011; Tomita et al. 2013; Kawai et al. 2014). Because of the low air temperature and strong winds in this period, sea surface turbulent (sensible plus latent) heat flux (Fig. 3g) was estimated to be noticeably high $\left(>700 \mathrm{~W} \mathrm{~m}^{-2}\right)$ in comparison with other periods. Moreover, the strengthened northerly wind over the Kuroshio enforced sea surface upward turbulent heat flux.

Turbulent heat flux and its related atmospheric and oceanic variables along the track during the high heat flux period from December 28 09:00 to December 29 20:00 (UTC) (track A in Fig. 3a) are shown with respect to latitude by red lines in Fig. 7. These values are averaged within intervals of approximately $2 \mathrm{~km}$, which is equivalent to a time average of approximately $30 \mathrm{~min}$. The A track crossed just north of the center of the MWS (Fig. 3a). For comparison, the variables observed along the track in the case of low turbulent heat flux from January 3 03:00 to January 5 03:00 (track B) are indicated by blue lines in Fig. 7. The B track is along the southern edge of the MWS. When the SD began to cross the B track, JRA-55based SLP was high west of the study region and low to the east and the background large-scale wind south of Japan was northerly (Fig. 6a and b). These background SLP and wind conditions are like those in the period of the A track; however, after that, the atmosphere rapidly became warm (Fig. 4b) in association with an SLP decline (Fig. 4c) due to the approach of a low-pressure system to the $\mathrm{B}$ track (Fig. 6c, d). Along the A and B tracks, the Kuroshio current axis, defined as the maximal sea surface current observed by the ADCP, was present at latitudes of $32.05^{\circ} \mathrm{N}$ and $31.60^{\circ} \mathrm{N}$, respectively. To compare the atmospheric and oceanic parameters around the Kuroshio current axis, the ordinates in Fig. 7 were adjusted relative to the location of the current axis to match the locations of the Kuroshio current axis along both tracks.

The Kuroshio MWS is found to not have a simple crosscurrent structure with a single SST peak (Fig. 7b). Large air-sea temperature differences (Fig. 7d) basically correspond to the high SST near the MWS. The maximum SST $\left(\sim 23^{\circ} \mathrm{C}\right)$ and large air-sea temperature difference on the A track (red line) within the MWS $\left(\sim 31.9^{\circ} \mathrm{N}\right)$ largely corresponds to the maximum wind speed $\left(>14 \mathrm{~m} \mathrm{~s}^{-1}\right)$ (red line in Fig. 7e). The intensification of wind over the SST maximum relative to the surrounding regions exceeds $2 \mathrm{~m} \mathrm{~s}^{-1}$ and is associated with an SLP depression of approximately $1 \mathrm{hPa}$ (red line in Fig. $7 \mathrm{~g}$ ). The turbulent heat flux reached a maximum of $1141 \mathrm{~W} \mathrm{~m}^{-2}$ (red line in Fig. 7a), which is much larger than wintertime climatological heat flux in the Kuroshio and Kuroshio Extension region $\left(\sim 600 \mathrm{~W} \mathrm{~m}^{-2}\right)$ (e.g., Konda et al. 2010; Sugimoto and Hanawa 2011).

Another SST peak around a latitude of $\sim 31.7^{\circ} \mathrm{N}$ on the A track (red line in Fig. 7b) is also accompanied by a wind speed peak (red line in Fig. 7e) and pressure depression (red line in Fig. $7 \mathrm{~g}$ ). The southwestward sailing SD reached the northern primary SST peak at 05:40 and southern secondary peak at 12:20 in local sidereal time (LST) before the expected peak time of diurnal SST cycle (circa 13:00 LST) studied by Koizumi (1956). The SD-observed SST decreased with time toward noon. As described above, the diurnal SST cycle is also not clear throughout the study period (Fig. 4a). Therefore, the SST peaks are principally attributable not to the diurnal SST cycle but to the intrinsic sea surface structure of the Kuroshio.

These SST and wind speed peaks yield remarkable turbulent sea surface heat flux peaks (red lines in Fig. 7a). The enhancements of latent heat flux in association with strengthened evaporation correspond to peaks in specific humidity (red line in Fig. 7f). Note that the moist air masses are considered to be advected from a little upstream of the A track. Associated with the atmospheric response, a peak in air pressure was exhibited between the depressions (red line in Fig. 7g). This submesoscale structure of SLP intensified the northwesterly wind over the SST peaks. This is consistent with the slightly high SSS observed around latitudes of $31.7^{\circ} \mathrm{N}$ and $31.9^{\circ} \mathrm{N}$ on the A track (red line in Fig. 7h), but differs from observed low SSS around the warm core during the summer by Taft (1978). This is probably because summer is not a season of active ocean heat release to the atmosphere.

It should be noted that the time series of air pressure (Fig. 4c) includes periodic variations probably due to the atmospheric tides. The power spectrum of this time series exhibits a significant peak at a semidiurnal period of $11.3 \mathrm{~h}$, which exceeds the $95 \%$ confidence interval. Meanwhile, no clear such periodic variations are displayed in the time series of SST (Fig. 4a) and air temperature (Fig. 4b). On the other hand, the submesoscale structure of SLP over the MWS of the Kuroshio is accompanied by the corresponding spatial changes in SST and other atmospheric variables, as described above. For this reason, the submesoscale SLP change over the MWS is considered to be caused not by the atmospheric semidiurnal tide but by the air-sea interaction in the MWS.

On the B track, which is along the southern edge of the MWS, SST and air-sea temperature difference peak 


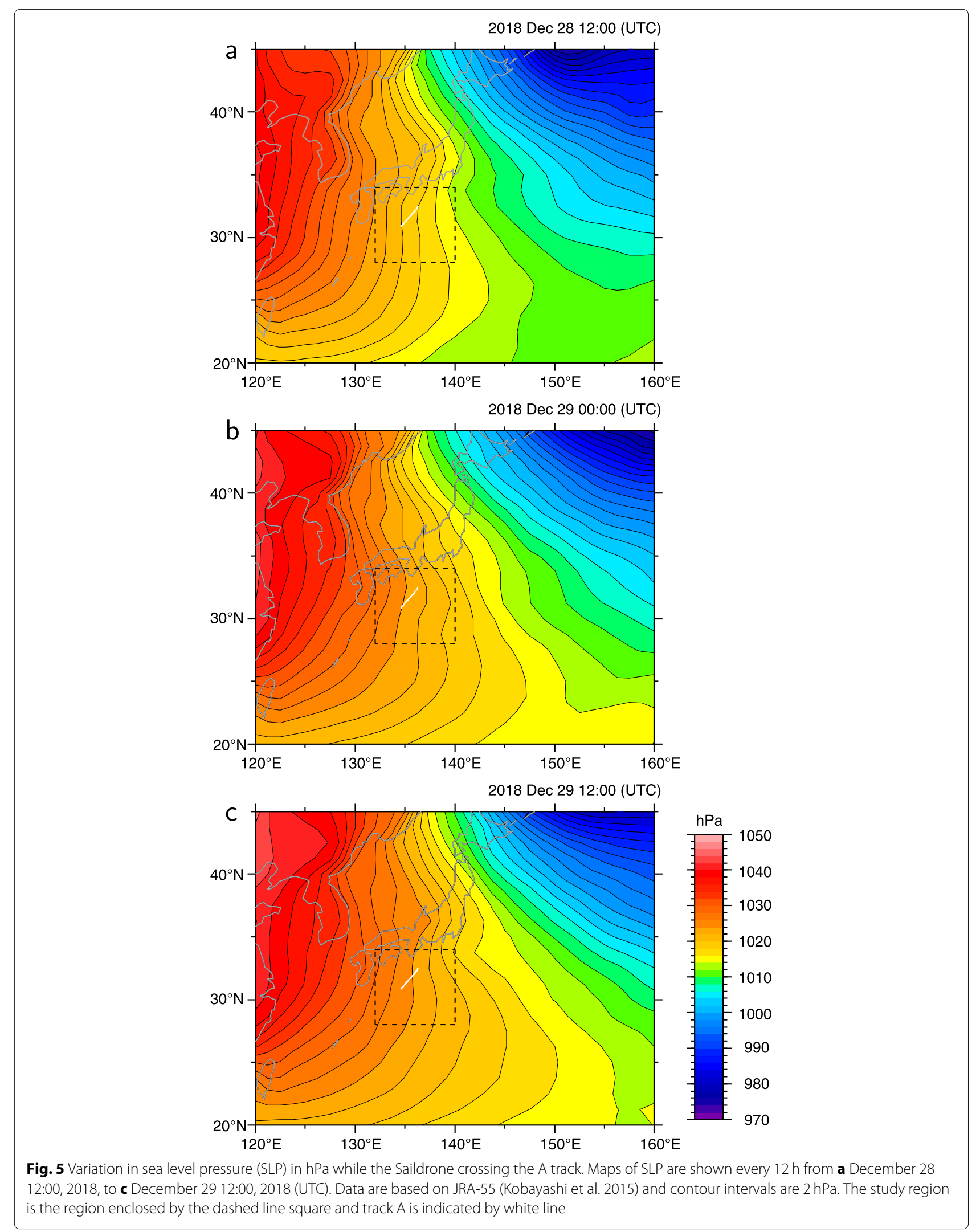



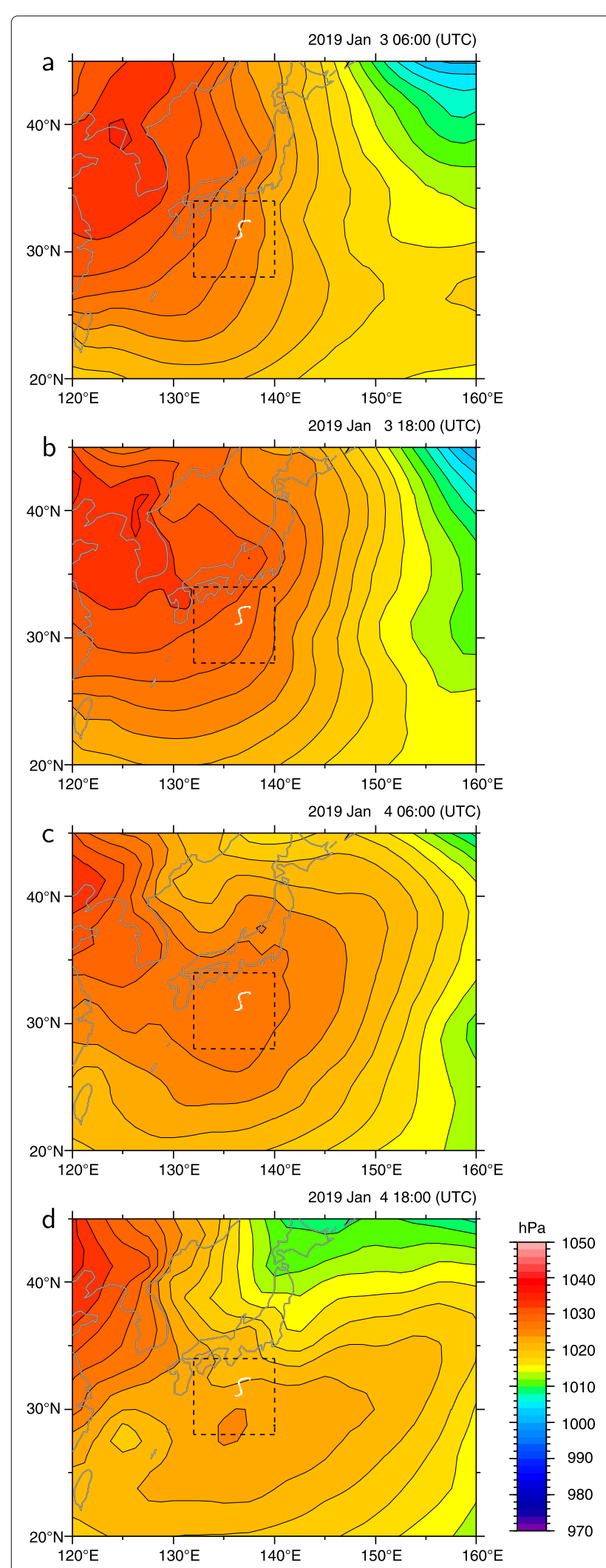

Fig. 6 Same as Fig. 5, but for the period of the B track from a January 3 06:00, 2019, to d January 4 18:00, 2019 (UTC) values were reduced (blue lines in Fig. 7b, d). As a lowpressure system approached to over the warm core of the Kuroshio, the southwestward sailing SD observed a steep pressure decrease of approximately $10 \mathrm{hPa}$ (blue line in Fig. 7g). Associated with the SLP decrease, the background northerly wind changed to the southwesterly weak wind (Fig. $3 \mathrm{f}$ and blue line in Fig. 7e). Consequently, the upward sea surface turbulent heat flux on the B track was smaller while the SD crossing the warm core of the Kuroshio $\left(<300 \mathrm{~W} \mathrm{~m}^{-2}\right)$ than the surrounding regions (blue line in Fig. 7a). The weakening in turbulent heat flux over the Kuroshio is, therefore, mostly caused by the weakening of wind due to the approach of the lowpressure system. The B track being apart from the MWS center, the influence of the Kuroshio warm core on the atmosphere is insignificant in comparison with the A track near the MWS center.

Large fluctuations in SSS were observed on the B track (blue line in Fig. 7h). However, as noted in "Methods/experimental" section, the SD-observed SSS data includes the sensor drift. Because the exact function form of the sensor drift is unknown, we should be cautious to make a comparison between absolute values of SSS along the $A$ and $B$ tracks. SSS values on the $B$ track such as at latitudes of $31.10-31.25^{\circ} \mathrm{N}$ and $31.48-31.55^{\circ} \mathrm{N}$ are low and values between these areas are high. The magnitudes of the fluctuations are approximately $0.2-0.3$ (psu), which are larger than the RMS difference. The high-salinity fluctuations are likely caused by evaporation and wind-driven mixing of underlying high salinity water derived from the North Pacific tropical water. Meanwhile, low-salinity fluctuations might be attributable to water freshened by rainfall due to the passage of an atmospheric low-pressure system on December 26, 2018, that was cooled by heat release and subducted to the sensor depth $(53 \mathrm{~cm})$.

Latent (sensible) heat flux, $F_{\mathrm{L}}\left(F_{\mathrm{S}}\right)$, is a function in terms of SST $T_{\mathrm{S}}$, air temperature $T_{\mathrm{A}}$, specific humidity $q$, and wind speed $U$. The spatial heat flux variation, $\Delta F$, is approximated as

$\Delta F \approx\left(\frac{\partial F}{\partial T_{\mathrm{S}}}\right) \Delta T_{\mathrm{S}}+\left(\frac{\partial F}{\partial T_{\mathrm{A}}}\right) \Delta T_{\mathrm{A}}+\left(\frac{\partial F}{\partial q}\right) \Delta q+\left(\frac{\partial F}{\partial U}\right) \Delta U$,

where $\Delta T_{\mathrm{S}}, \Delta T_{\mathrm{A}}, \Delta q$, and $\Delta U$ are spatial variations in SST, air temperature, specific humidity, and wind speed, respectively. To examine which variables dominantly contribute to the turbulent heat flux, we decomposed the heat flux variations into the variation components due to the four variables on the basis of Eq. (1). Because the turbulent heat flux function form is not simple, each term of the right hand side (RHS) of Eq. (1) in this study was evaluated as the rate of the change of a variable by using the mean values for the other three variables on each SD track. 


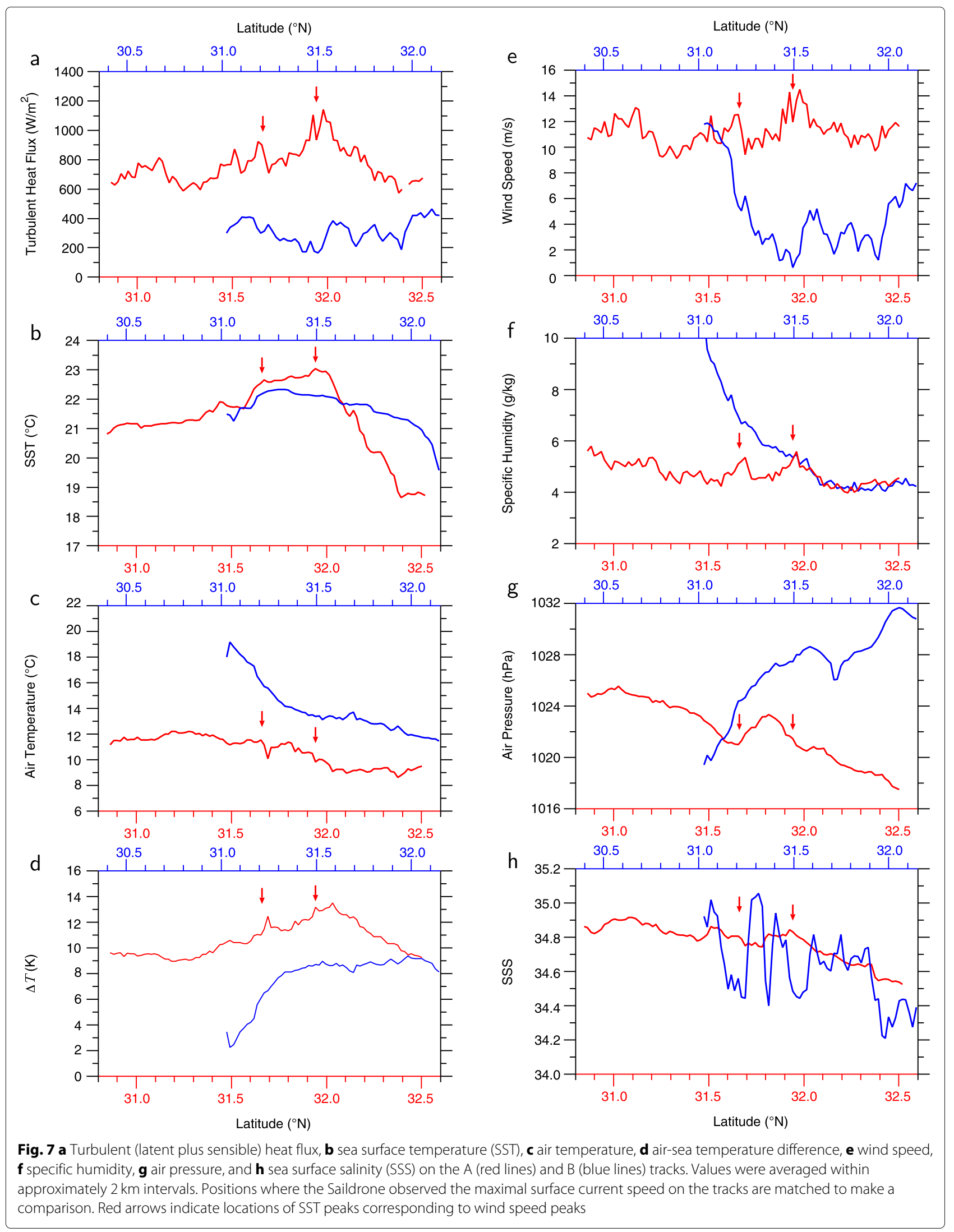


Figure $8 \mathrm{a}$ and $\mathrm{b}$ show the respective contributions of the variables for latent and sensible heat fluxes on the A track. The sums of the contributions to the variations in both latent and sensible heat fluxes from the four variables, the RHS of Eq. (1), are in good agreement with the variations in $\Delta F$, the left hand side (LHS) of the equation (Fig. 9). Wind speed intensification is found to be the largest positive factor for both latent and sensible heat fluxes around the warm core of the Kuroshio (orange lines in Fig. 8). Remarkably, spatial variation of the heat fluxes on scales of approximately $0.1^{\circ}$ latitude $(\sim 10 \mathrm{~km})$ and smaller are almost solely attributable to wind speed variations. In particular, the widths of wind peaks are approximately $10 \mathrm{~km}$ or slightly more. The peak winds primarily contributed to the latent (sensible) heat flux in the MWS around latitudes of $32.0^{\circ} \mathrm{N}$ and $31.6^{\circ} \mathrm{N}$ by approximately 170 (70) and 70 (30) $\mathrm{W} \mathrm{m}^{-2}$, respectively. The contribution of peak SST to the latent (sensible) heat flux, which is approximately 70 (30) $\mathrm{W} \mathrm{m}^{-2}$, is secondary (magenta lines). Although air temperature and specific humidity have less effect on the heat fluxes than wind speed and SST near the current axis of the Kuroshio, a cold air mass from the continent intensifies the sensible heat flux on the onshore side of the Kuroshio (green line in Fig. 8b).

On the B track (Fig. 10a, b), latent and sensible heat fluxes are reduced in the Kuroshio owing principally to the attenuation of wind due to the approach of the lowpressure system. In comparison with the A track, the RHS of Eq. (1) on the B track underestimates the attenuation of the latent and sensible heat releases to the atmosphere due to the large wind speed change while the low-pressure system approaching to the south of $32.0^{\circ} \mathrm{N}$ (Fig. 11). The discrepancies for the latent and sensible heat fluxes are not more than approximately $50 \mathrm{~W} \mathrm{~m}^{-2}$ and $40 \mathrm{~W} \mathrm{~m}^{-2}$,

Latitude $\left({ }^{\circ} \mathrm{N}\right)$
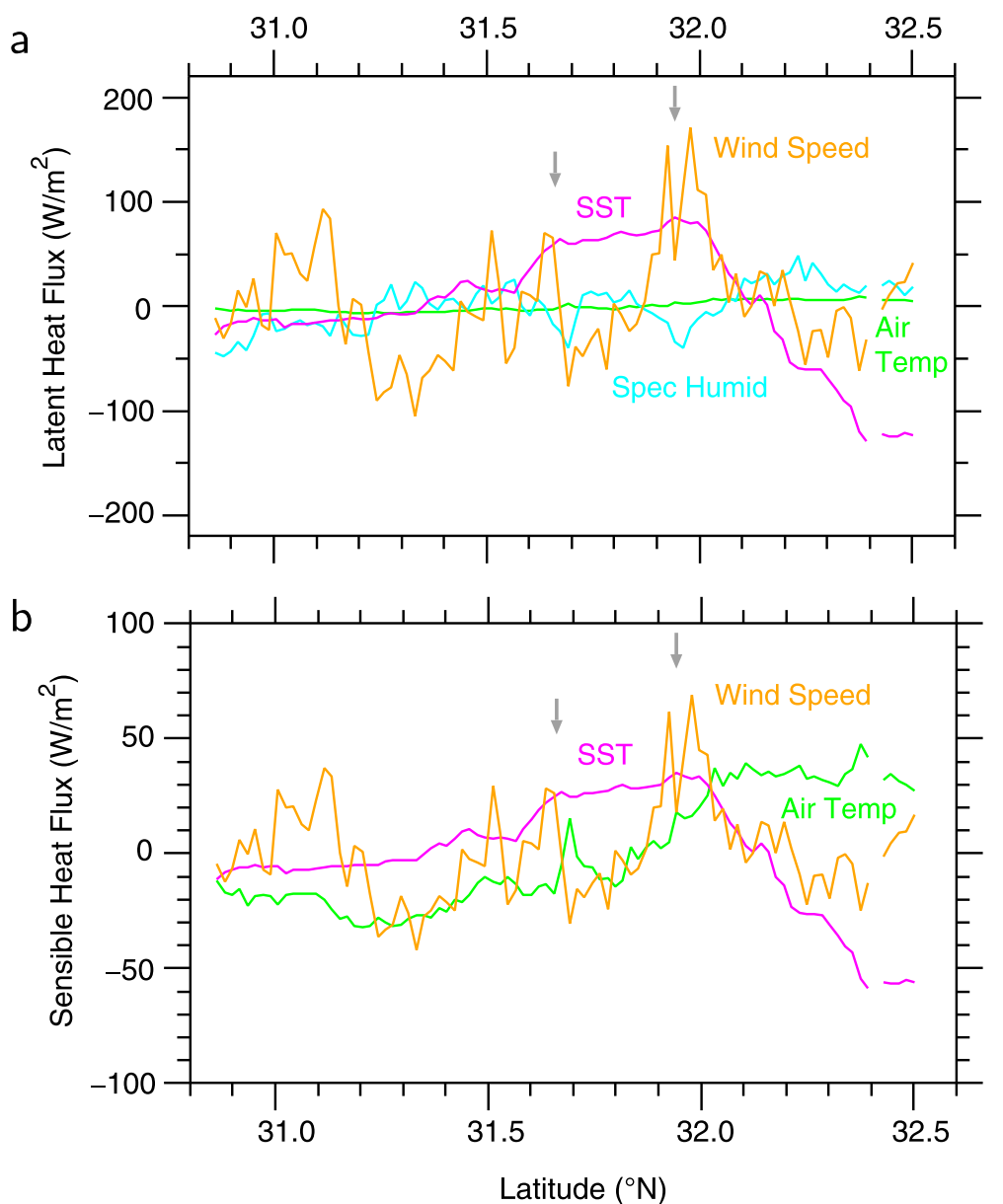

Fig. 8 Spatial variation components in a latent and $\mathbf{b}$ sensible heat fluxes on track $A$ due to wind speed, ( $\left.\partial F / \partial U_{W}\right) \Delta U_{W}$ in Eq. (1) (orange line), sea surface temperature (SST) $\left(\partial F / \partial T_{S}\right) \Delta T_{S}$ (magenta line), air temperature ( $\left.\partial F / \partial T_{A}\right) \Delta T_{A}$ (green line), and specific humidity $(\partial F / \partial q) \Delta q$ (cyan line). Values were averaged within intervals of approximately $2 \mathrm{~km}$. Gray arrows are the same as the red arrows in Fig. 7. In $\mathbf{b}$, sensible heat flux variations due to specific humidity variations are not plotted because sensible heat flux is independent of specific humidity 


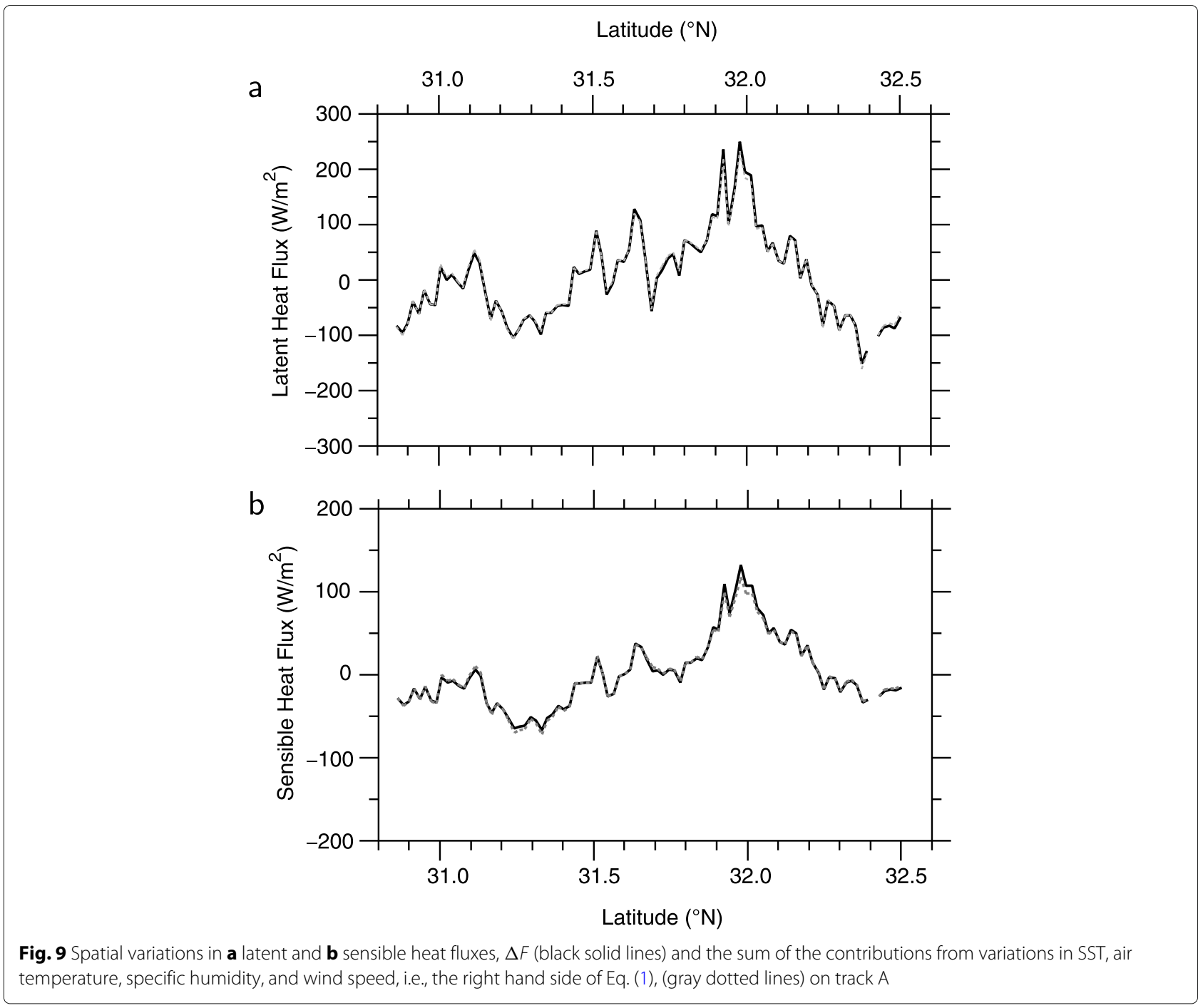

respectively. Despite the discrepancies, the spatial patterns of the RHS and LHS of Eq. (1) on the B track are similar to each other. Thus, it is certain that the wind variation is responsible to the attenuation in turbulent heat fluxes.

Despite such a large heat release observed on the A track, the Kuroshio MWS continued to exist for at least approximately 2 weeks, as mentioned previously. If the MWS is $50 \mathrm{~m}$ thick, a monthly mean value of winter net heat flux $\left(\sim 600 \mathrm{~W} \mathrm{~m}^{-2}\right)$ near the Kuroshio current axis (e.g., Tomita et al. 2019) is evaluated to reduce the water temperature at a rate of $\sim 0.3 \mathrm{Kd}^{-1}$. This evaluated temperature decrease rate is too large to allow the very high SST of the MWS to be maintained for 2 weeks. Additionally, because the Kuroshio current speed $\left(>2 \mathrm{~m} \mathrm{~s}^{-1}\right)$ is very fast, disturbances are passively advected by the Kuroshio (e.g., Nagano and Kawabe 2005), unlike the MWS. Therefore, the heat content in the MWS should be supplied by the continuing local horizontal current convergence. As shown in the map of horizontal divergence of currents based on OSCAR data (Fig. 12), the MWS centered at approximately $31.5^{\circ} \mathrm{N}, 135.8^{\circ} \mathrm{E}$ is found to be in the convergence (or no significant divergence) regions. Although the examination cannot be conclusive evidence as OSCAR data are derived from spatially low-resolution satellite data, the MWS might be maintained by the convergence of warm surface water. This can be clarified by future well-organized observations using unmanned surface vehicles such as SDs.

\section{Summary and discussion}

SDs can finish observations of atmosphere and ocean variations on mesoscale or smaller scales in fairly short times without disturbing the variations. Therefore, SDs are considered to reveal more exact mesoscale or smaller scale oceanic effects on the atmospheric boundary layer than 
Latitude $\left({ }^{\circ} \mathrm{N}\right)$
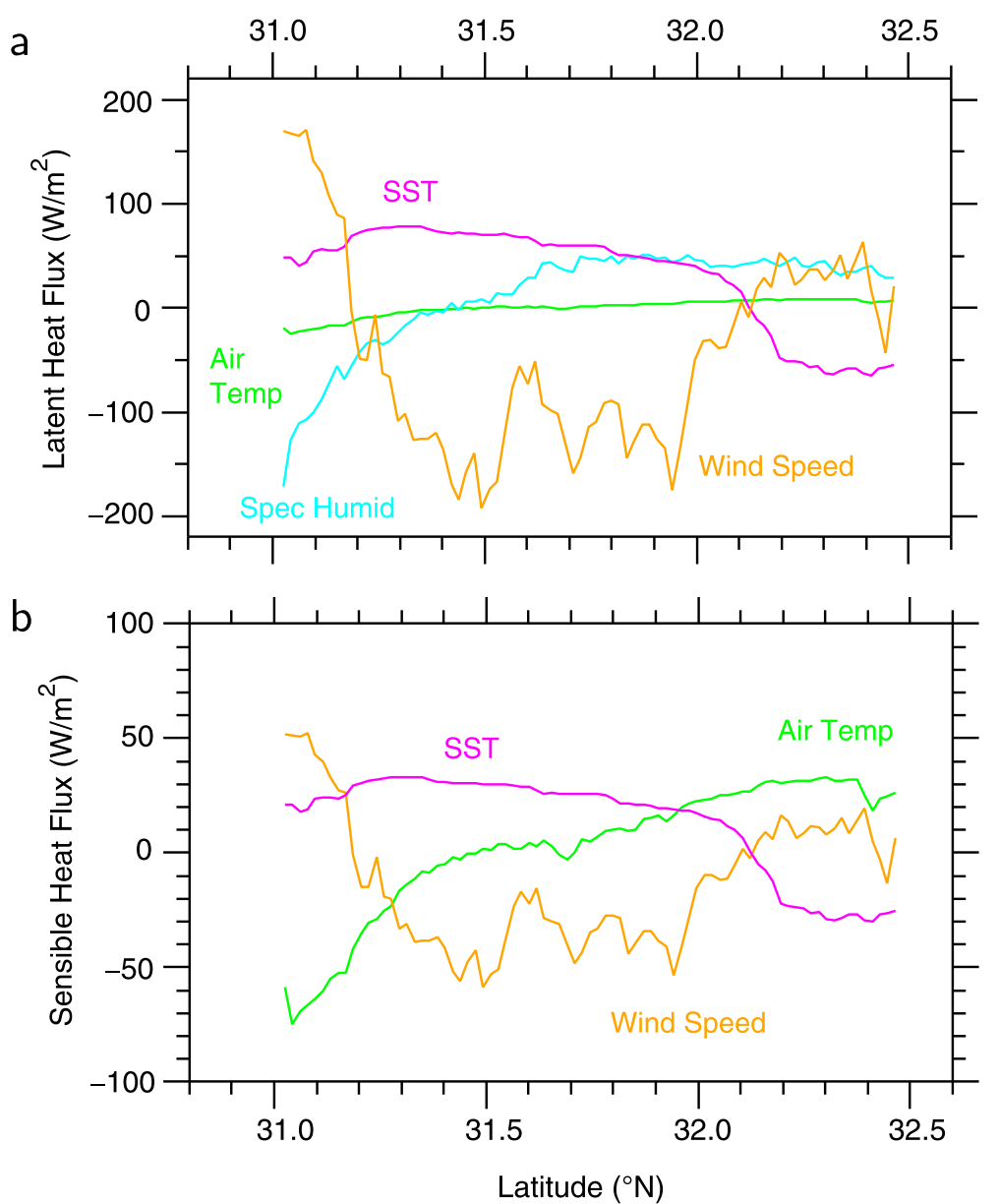

Fig. 10 Same as Fig. 8, but for track B

other methods such as by using only research vessels, satellites, and data assimilation techniques. Using an SD, we performed high-resolution $(\sim 2 \mathrm{~km})$ measurements of atmospheric and oceanic variables across the Kuroshio south of Japan from December 21, 2018, to January 8, 2019. Based on satellite SST and SSH observations, we found that the SD passed near the center of a locally very warm spot in the Kuroshio, referred to as a mesoscale warm spot (MWS) in this paper, around $31.5^{\circ} \mathrm{N}, 135.8^{\circ}$ E. This MWS has dimensions of approximately 100 and $50 \mathrm{~km}$ parallel and perpendicular to the Kuroshio, respectively, and a very warm $\left(>23^{\circ} \mathrm{C}\right)$ water mass around its center.

The SD observation revealed smaller, i.e., submesoscale, features of atmospheric and oceanic variables around the Kuroshio MWS. From December 28 to December 29, 2018, the SD crossed just north of the MWS center (track A). Two SST peaks were exhibited across the MWS. The SST value of the primary peak on the track nearest the
MWS center was $\sim 23^{\circ} \mathrm{C}$. Furthermore, the MWS affects wind and SLP. The peak widths of wind speed and associated heat flux are approximately $10 \mathrm{~km}$ or slightly more. Corresponding to the two SST peaks within the MWS, the wind was enhanced by approximately $2 \mathrm{~m} \mathrm{~s}^{-1}$ over the MWS, reaching a maximum of $14 \mathrm{~m} \mathrm{~s}^{-1}$. As a result, the sea surface turbulent (latent plus sensible) heat flux was enhanced to upwards of $1141 \mathrm{~W} \mathrm{~m}^{-2}$. Local heat convergence due to horizontal currents is anticipated to maintain the persistent high SST feature of the Kuroshio MWS.

Associated with the enhancements of the northerly winter monsoon wind over the SST peaks just north of the center of the MWS, i.e., on the A track, SLP was observed to be depressed by approximately $1 \mathrm{hPa}$. An SLP peak was observed between the depressions. As these wind and SLP changes appear to be in the geostrophic balance, the observed characteristics of the oceanic and atmospheric variables are consistent with the pressure adjustment mechanism that Lindzen and Nigam (1987) and 


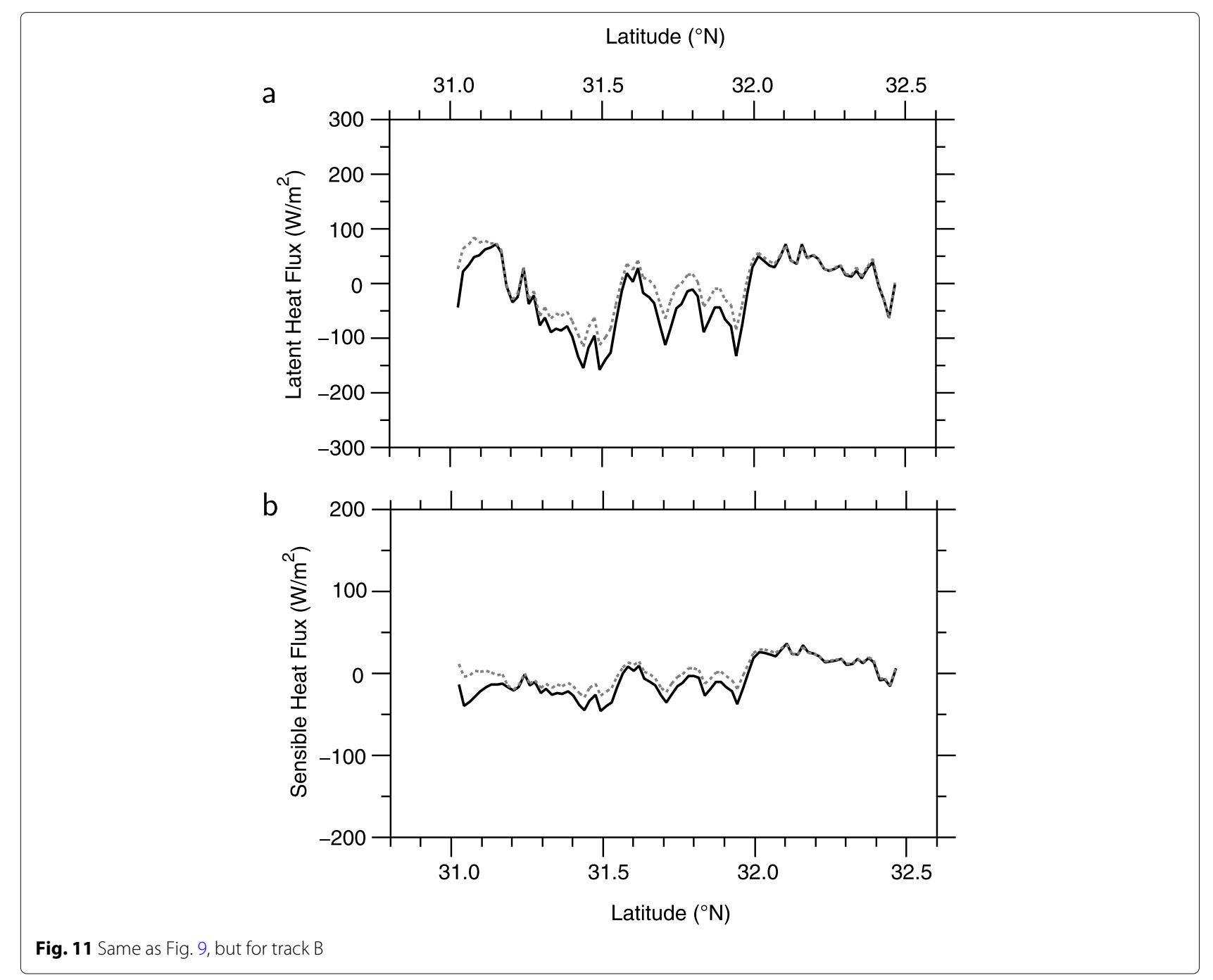

others proposed. While the SD crossed the southern edge of the MWS from January 3 to January 5, 2019 (track B), the background strong northerly wind changed to southwesterly weak wind in association with an SLP decrease of $\sim 10 \mathrm{hPa}$ due to the approach of a low-pressure system. The weakening of the wind reduced heat release to the atmosphere while the SD crossing the Kuroshio warm core.

It is noteworthy that, on the A track, we observed the submesoscale structure of SLP on a spatial scale of $\sim 15 \mathrm{~km}$ across the Kuroshio MWS, which is related to the strengthening of the northwesterly wind over the SST peaks. This submesoscale SLP structure has not been shown by previous studies but can be interpreted by threedimensional ageostrophic convective circulations induced by a horizontal SST difference, as studied by Dalu and Pielke (1993) for example. Because over the onshore (32.0 $\mathrm{N})$ and offshore $\left(31.6^{\circ} \mathrm{N}\right)$ edges of the MWS, where SST is maximal, uplifts of air occur in association with the low pressures, cold dry air flows toward the edges from outside the MWS. Around the central part of the MWS, there appears a descending flow and pressure enhancement between the pressure depressions. Such a pair of ageostrophic vortices induces convergences of warm water toward the MWS and increases SST near the MWS edges. This air-sea interaction is a positive feedback mechanism, which is considered to maintain the observed submesoscale structures across the MWS.

In previous studies based on low-resolution reanalysis data and so on, the influences of large-scale oceanic disturbances on the atmosphere have been obtained by averaging a large number of data. Meanwhile, in this study, the SD "snapshot" observations revealed submesoscale structures of atmosphere and ocean in the MWS of the Kuroshio unresolved in previous studies. Smirnov et al. (2015), for instance, examined how the atmospheric response to the Oyashio (the subarctic western boundary current) SST front depends on spatial resolutions of 


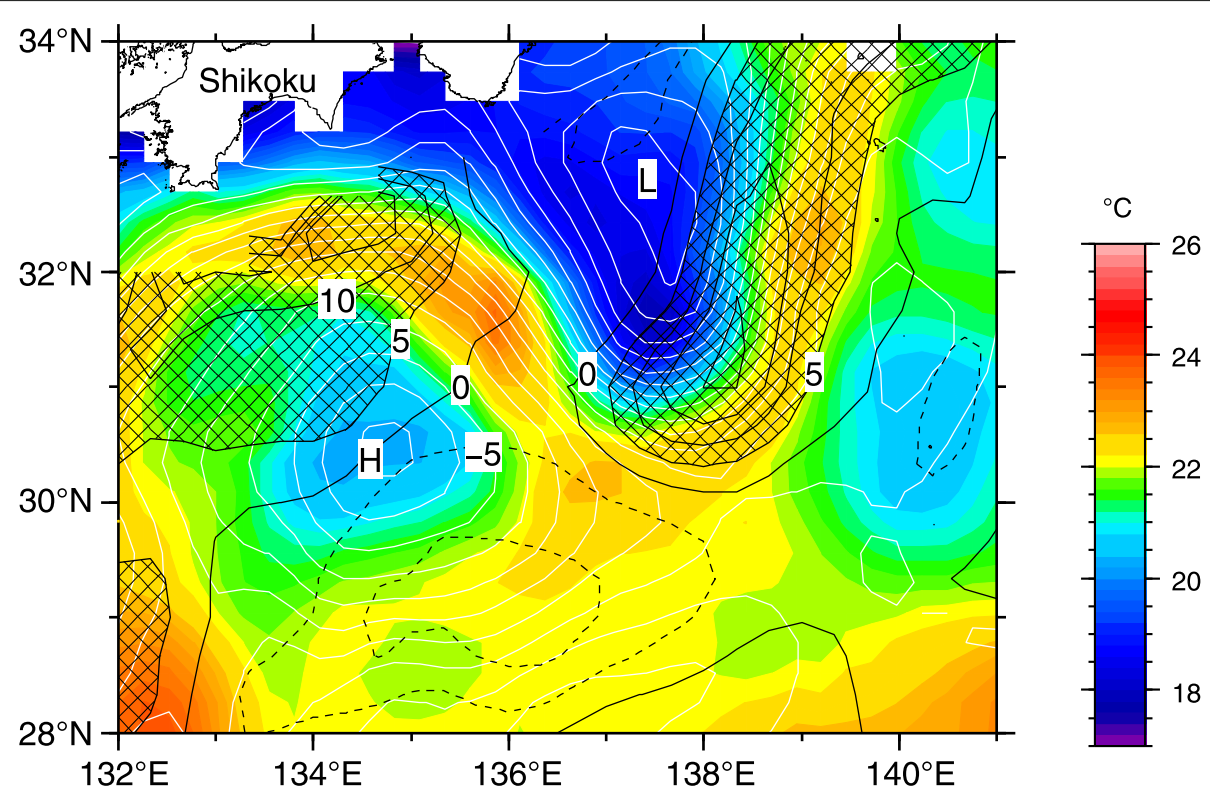

Fig. 12 Sea surface current divergence $\left(10^{-6} \mathrm{~s}^{-1}\right.$, black contours), sea surface temperature $\left({ }^{\circ} \mathrm{C}\right.$, color shading), and sea surface height ( $\mathrm{cm}$, white contours). Contour intervals of current divergence and SSH are $5 \times 10^{-6} \mathrm{~s}^{-1}$ and $10 \mathrm{~cm}$, respectively. Meshing indicates regions where current divergence is greater than $5 \times 10^{-6} \mathrm{~s}^{-1}$. Current divergence was derived from OSCAR data prepared by Bonjean and Lagerloef (2002)

numerical models. In their high-resolution $\left(0.25^{\circ}\right.$ grid $)$ experiment, transient eddy ( $2-6$ days timescales) variability is greater than the mean wind, whereas, in the lowresolution $\left(1^{\circ}\right.$ grid) experiment, the mean wind dominates the eddy variability. High-resolution SD observations permit us to reveal the oceanic impact on the atmosphere as the changes of the overlying wind on a spatial scale of approximately $10 \mathrm{~km}$ and are also useful for improvements in data assimilation and coupled ocean-atmosphere models.

\begin{abstract}
Abbreviations
ADCP: Acoustic Doppler current profiler; COARE: Coupled Ocean-Atmosphere Response Experiment; CT: Conductivity-temperature; CTD: Conductivitytemperature-depth; $\mathrm{CTDO}_{2}$ : Conductivity-temperature-depth-oxygen; JAMSTEC: Japan Agency for Marine-Earth Science and Technology JRA-55: Japanese 55-year Reanalysis; LHS: Left hand side; MWS: Mesoscale warm spot; NOAA: U.S. National Oceanic and Atmospheric Administration; OSCAR: Ocean Surface Current Analysis Real-time; RHS: Right hand side; RMS:

Root-mean-square; SD: Saildrone; SLP: Sea level pressure; SSH: Sea surface height; SSS: Sea surface salinity; SST: Sea surface temperature
\end{abstract}

\section{Acknowledgements}

SD observations were performed as a part of JAMSTEC 2018-2019 Saildrone Missions. The deployment and recovery of the SD at a port in Guam, data collection, and calibration were undertaken by SAILDRONE Inc. (https://www. saildrone.com). The authors thank the editor, Prof. Akira Oka (Atmosphere and Ocean Research Institute, The University of Tokyo) and anonymous reviewers for constructive comments.

\section{Authors' contributions}

AN proposed the topic, conceived, designed the study, analyzed the data, and constructed the manuscript. KA organized the Saildrone observation and collaborated with the corresponding author in the construction of manuscript. Both authors read and approved the final manuscript.

\section{Funding}

This work was partly supported by the Japan Society for the Promotion of Science (JSPS), Grant-in-Aid for Scientific Research (17K05660, 20K04072).

\section{Availability of data and materials}

Kuroshio Saildrone data were obtained as a part of JAMSTEC Saildrone Mission and are available on request to the corresponding author. We are preparing a website for distributing the data of this mission. Gridded SST and altimetric SSH data were provided by the U.S. National Oceanic and Atmospheric Administration/Earth System Research Laboratory, Physical Sciences Division (http://www.esrl.noaa.gov/psd/) and Copernicus Marine Environment Monitoring Service (http://marine.copernicus.eu), respectively. JRA-55 sea level pressure data were provided by the Japan Meteorological Agency. The OSCAR products were provided by Physical Oceanography Distributed Active Archive Center (PO.DAAC) (https://podaac.jpl.nasa.gov).

\section{Competing interests}

The authors declare that they have no competing interest.

Received: 3 February 2020 Accepted: 4 August 2020

Published online: 26 August 2020

\section{References}

Bonjean F, Lagerloef GSE (2002) Diagnostic model and analysis of the surface currents in the tropical Pacific Ocean. J Phys Oceanogr 32(10):2938-2954

Bryden HL, Imawaki S (2001) Ocean heat transport. In: Siedler H, Church J, Gould J (eds). Ocean circulation and climate: observing and modeling the global ocean. Academic Press, London. pp 455-474

Dalu GA, Pielke RA (1993) Vertical heat fluxes generated by mesocale atmospheric flow induced by thermal inhomogeneities in the PBL. J Atmos Sci 50:919-926

Fairall CW, Bradley EF, Hare JE, Grachev AA, Edson JB (2003) Bulk parameterization of air-sea fluxes: updates and verification for the COARE algorithm. J Clim 16:571-591

Fuglister FC, Worthington LV (1951) Some results of a multiple ship survey of the Gulf Stream. Tellus 3(1):1-14

Hayes SP, McPhaden MJ, Wallace JM (1989) The influence of sea-surface temperature on surface wind in the eastern equatorial Pacific: weekly to monthly variability. J Clim 2:1500-1506 
Hsiung J (1986) Mean surface energy fluxes over the global ocean. J Geophys Res 91(C9):10585-10606. https://doi.org/10.1029/JC091iC09p10585

Kawai Y, Tomita H, Cronin MF, Bond NA (2014) Atmospheric pressure response to mesoscale sea surface temperature variations in the Kuroshio Extension region: in situ evidence. J Geophys Res 119:8015-8031. https://doi.org/10. 1002/2013JD021126

Kobayashi S, Ota Y, Harada Y, Ebita A, Moriya M, Onoda H, Onogi K, Kamahori H, Kobayashi C, Endo H, Miyaoka K, Takahashi K (2015) The JRA-55 reanalysis: general specifications and basic characteristics. J Meteor Soc Jpn 93(1):5-48. https://doi.org/10.2151/jmsj.2015-001

Koizumi M (1956) Researches on variations of oceanographic conditions in the region of the ocean weather station "extra" in the North Pacific Ocean (IV)-on the diurnal variations in air and sea-surface temperatures-. Pap Meteor Geophys 7:144-154

Konda M, Ichikawa H, Tomita H, Cronin MF (2010) Surface heat flux variations across the Kuroshio Extension as observed by surface flux buoys. J Clim 23(19):5206-5221. https://doi.org/10.1175/2010JCLI3391.1

Lindzen RS, Nigam S (1987) On the role of sea surface temperature gradients in forcing low-level winds and convergence in the tropics. J Atmos Sci 44(17):2418-2436

Manley JE (2008) Unmanned surface vehicles, 15 years of development. In: OCEANS 2008, Quebec City. pp 1-4. https://doi.org/10.1109/OCEANS. 2008.5152052

Meinig C, Lawrence-Slavas N, Jenkins R, Tabisola HM (2015) The use of saildrones to examine spring conditions in the Bering Sea: vehicle specification and mission performance. In: OCEANS 2015 - MTS/IEEE Washington, Washington, DC. pp 1-6. https://doi.org/10.23919/OCEANS. 2015.7404348

Nagano A, Kawabe M (2005) Coastal disturbance in sea level propagating along the south coast of Japan and its impact on the Kuroshio. J Oceanogr 61:885-903. https://doi.org/10.1007/s10872-006-0007-0

Nagano A, Ichikawa K, Ichikawa H, Konda M, Murakami K (2009) Synoptic flow structures in the confluence region of the Kuroshio and the Ryukyu Current. J Geophys Res 114(C06007). https://doi.org/10.1029/2008JC005213

Nagano A, Ichikawa K, Ichikawa H, Tomita H, Tokinaga H, Konda M (2010) Stable volume and heat transports of the North Pacific subtropical gyre revealed by identifying the Kuroshio in synoptic hydrography south of Japan. J Geophys Res 115(C09002). https://doi.org/10.1029/2009JC005747

Nagano A, Yamashita Y, Hasegawa T, Ariyoshi K, Matsumoto H, Shinohara M (2019) Characteristics of an atypical large-meander path of the Kuroshio current south of Japan formed in September 2017. Mar Geophys Res 40(4):525-539. https://doi.org/10.1007/s11001-018-9372-5

Nitani H (1972) Beginning of the Kuroshio. In: Stommel H, Yoshida K (eds). Kuroshio-its physical aspects. University of Tokyo Press, Tokyo. pp 129-163

Reynolds RW, Smith TM, Liu C, Chelton DB, Casey KS, Schlax MG (2007) Daily high-resolution-blended analyses for sea surface temperature. J Clim 20:5473-5496. https://doi.org/10.1175/2007JCLI1824.1

Rio MH, Guinehut S, Larnicol G, J Geophys Res (2011) New CNES-CLS09 global mean dynamic topography computed from the combination of GRACE data, altimetry, and in situ measurements 116(C07018). https://doi.org/10. 1029/2010JC006505

Smirnov D, Newman M, Alexander MA, Kwon Y-O, Frankignoul C (2015) Investigating the local atmospheric response to a realistic shift in the Oyashio sea surface temperature front. J Clim 28:1126-1147. https://doi. org/10.1175/JCLI-D-14-00285.1

Sugimoto S, Hanawa K (2011) Roles of SST anomalies on the wintertime turbulent heat fluxes in the Kuroshio-Oyashio confluence region: influences of warm eddies detached from the Kuroshio Extension. J Clim 24:6551-6561. https://doi.org/10.1175/2011JCLI4023.1

Taft B (1978) Structure of Kuroshio south of Japan. J Mar Res 36:77-117

Tanimoto Y, Kanenari T, Tokinaga H, Xie S-P (2011) Sea level pressure minimum along the Kuroshio and its extension. J Clim 24:4419-4434. https://doi.org/ 10.1175/2011 JCLI4062.1

Tokinaga H, Tanimoto Y, Nonaka M, Taguchi B, Fukamachi T, Xie S-P, Nakamura H, Watanabe T, Yasuda I (2006) Atmospheric sounding over the winter Kuroshio Extension: effect of surface stability on atmospheric boundary layer structure. Geophys Res Lett 33(L04703). https://doi.org/10.1029/ 2005GL025102

Tomita H, Xie S-P, Tokinaga H, Kawai Y (2013) Cloud response to the meandering Kuroshio Extension front. J Clim 26:9393-9398. https://doi. org/10.1175/JCLI-D-13-00133.1
Tomita H, Hihara T, Kako S, Kubota M, Kutsuwada K (2019) An introduction to J-OFURO3, a third-generation Japanese ocean flux data set using remote-sensing observations. J Oceanogr 75:171-194. https://doi.org/10. 1007/s10872-018-0493-x

Wallace JM, Mitchell TP, Deser C (1989) The influence of sea-surface temperature on surface wind in the eastern equatorial Pacific: seasonal and interannual variability. J Clim 2:1492-1499

Worthington LV, Kawai H (1972) Comparison between deep sections across the Kuroshio and the Florida Current and Gulf Stream. In: Stommel H, Yoshida K (eds). Kuroshio-its physical aspects. University of Tokyo Press, Tokyo. pp 371-385

Zhang D, Cronin MF, Meinig C, Farrar JT, Jenkins R, Peacock D, Keene J, Sutton A, Yang Q (2019) Comparing air-sea flux measurements from a new unmanned surface vehicle and proven platforms during the SPURS-2 field campaign. Oceanography 32(2):122-133. https://doi.org/10.5670/ oceanog.2019.220

\section{Publisher's Note}

Springer Nature remains neutral with regard to jurisdictional claims in published maps and institutional affiliations.

\section{Submit your manuscript to a SpringerOpen ${ }^{\circ}$ journal and benefit from:}

- Convenient online submission

Rigorous peer review

- Open access: articles freely available online

- High visibility within the field

- Retaining the copyright to your article

Submit your next manuscript at $>$ springeropen.com 